\title{
The Discursive Dynamics of Disclosure and Avoidance: Evidence from a Study of Infertility
}

\author{
Jennifer J. Bute, Ph.D. \\ Indiana University-Purdue University, Indianapolis
}

[This is an Accepted Manuscript of an article published by Taylor \& Francis Group in Western Journal of Communication on February 7, 2013, available online:

http://dx.doi.org/10.1080/10570314.2012.695425]

Author Note

Jennifer J. Bute (Ph.D., University of Illinois at Urbana-Champaign) is an assistant professor in the Department of Communication Studies at Indiana University-Purdue University, Indianapolis.

This manuscript is based on the author's dissertation under the direction of Daena J. Goldsmith. A version of this paper was presented at the April 2011 meeting of the Central States Communication Association. I would like to thank Bill Eadie and two anonymous reviewers for their thoughtful comments and helpful feedback on this manuscript.

Correspondence should be addressed to Jennifer J. Bute, Department of Communication Studies, Indiana University-Purdue University Indianapolis, 309 Cavanaugh Hall, Indianapolis, IN, 46202. Email: jjbute@iupui.edu. 


\begin{abstract}
Recent research and theorizing about privacy management suggests a need to consider discursive dynamics and interpretations of meaning in conversations involving disclosure, topic avoidance, secret-keeping, and other privacy management processes. In the following study, I drew on a specific set of theoretical assumptions as the basis for an investigation of privacy management in the context of infertility. Based on in-depth interviews with 23 women coping with infertility, results reveal the varied ways that private topics arose in conversations (e.g., discloser initiated conversations, responses to requests for information), the diverse ways that women concealed or revealed their struggles with infertility, and the multiple dilemmas they faced in managing private information about their fertility problem. I discuss the results in light of the extant literature on managing private information about sensitive issues and suggest that scholars must continue to focus on conversational dynamics to understand fully how privacy management processes unfold in everyday conversations.
\end{abstract}


The Discursive Dynamics of Disclosure and Avoidance: Evidence from a Study of Infertility

Privacy management processes like disclosure and topic avoidance, have intrigued scholars of communication for decades (Altman \& Taylor, 1973; Derlega, Metts, Petronio, \& Margulis, 1993, Petronio, 2002). The plethora of research in this area has led to a rich understanding of the individual and relational outcomes related to privacy management and the various criteria individuals consider when deciding whether to reveal sensitive, risky, or personal information (e.g., Greene, Derlega, Yep, \& Petronio, 2003). However, the majority of studies examining privacy management reveal little about the conversations in which such communicative processes unfold.

The goal of this study is to illumine the discursive dynamics of disclosure and topic avoidance through attention to how topics arise in conversations, how topics are discussed (or not), and the meanings people associate with such interactions. Drawing on in-depth interviews with women coping with infertility and building on key assumptions from communication privacy management theory (CPM; Petronio, 2002), I explored discursive dynamics in an effort to contribute to ongoing scholarly conversations about privacy management. In the following pages, I articulate the importance of focusing on discursive practices and attributions of meaning, elucidate the theoretical underpinnings and methodological approach of this study, and describe women’s recollections of memorable conversations about their infertility.

\section{Expanding Work on Disclosure and Avoidance}

Despite recent work in the privacy genre drawing attention to the intricacies of conversational moments (Afifi \& Steuber, 2009; Caughlin, et al., 2008; Caughlin, et al., 2009), investigations of discursive dynamics and attributions of meaning remain in the minority. Attention to discursive practices and interpretations of conversations serves a key theoretical 
function as scholars moved beyond the conceptualization of disclosure and avoidance as a bivariate construct and work to "decenter” the assumption of the sovereign self in research and theorizing (Baxter \& Sahlstein, 2000, p. 292). Evidence also suggests that how people reveal private information has important consequences that merit further investigation.

\section{Beyond Bivariate}

Understanding discursive dynamics is necessary to move beyond overly simplistic characterizations that suggest that disclosure is a bivariate construct and that avoidance is the opposite of disclosure (Afifi, Caughlin, \& Afifi, 2007). Even the many studies that have attempted to understand levels or patterns of disclosure often revealed little about how a topic comes up or what is said. For instance, researchers have measured levels of disclosure about various topics on an interval scale (e.g., rating disclosures on a scale ranging from 0 to 4 where 0 $=$ talked about none of what I felt and $4=$ talked about all of what I felt; Figueiredo, Fries, \& Ingram, 2004). Such scales tell us nothing about the topics people discussed when they talked about "all of what they felt" (or how they avoided talking if they reported a zero for a certain item). Thus, the nuanced and emergent nature of disclosure and avoidance has been overlooked.

\section{Beyond the Sovereign Self}

The choice to reveal or conceal information is often conceptualized as an intact decision brought to an interaction after a careful weighing of pros and cons, or explained after careful reflection. Such a conceptualization implies that communicative decisions are the result of "an intrapersonal mental calculation inside an actor's head” (Baxter \& Sahlstein, 2000, p. 290) in which an individual conducts an economic analysis of risks and benefits. While individuals undoubtedly engage in cognitive processes in which they ponder privacy management decisions, approaching disclosure, avoidance, and secrecy only "as an individual process that is rational and 
driven by choice” (p. 292), neglects the ongoing, negotiated, and emergent nature of privacy management as it unfolds in everyday conversations. Conversational dynamics, such as how a topic arises and how people make meaning of conversations, suggest that disclosure and avoidance are not always a matter of one individual's personal choice but are also prompted by communicative actions of conversational partners (Bute, 2009; Coupland, Coupland, \& Giles, 1991).

\section{The Consequences of How People Avoid or Disclose}

Finally, a study explicating discursive dynamics is necessary because evidence suggests that how people avoid or disclose a topic in everyday conversations can matter very much (e.g., Silver, Wortman, \& Crofton, 1990). For instance, research has suggested that when people disclose that they are HIV positive, disclosure messages with an explicit goal of preventing leakage of the information (e.g., "I have not really told many people about this yet, and I would hope that you will keep this just between us.”) might be less likely to elicit emotional support and relational assurance than other types of messages that do not include this explicit goal (Caughlin et al., 2009). Whether parents respond to a child's coming out more or less favorably can depend on whether their children reveal their homosexuality directly (i.e., as opposed to situations in which parents hear the news from a third party) and whether they do so in person (Ben-Ari, 1995a; 1995b). Finally, when people reveal a distressing situation, such as their struggles with cancer, confidants might be more likely to respond supportively when displays of distress are counterbalanced by evidence of coping efforts (Silver et al., 1990). Overall, these studies have suggested that conversational dynamics are tied to important outcomes. 


\section{Studying Privacy in the Infertility Context}

The infertility context is particularly fruitful for studying issues of privacy, as many who have dealt with a fertility problem report the tension between a desire to keep the situation private and the way that information related to pregnancy and childbearing is frequently treated as public information (Miall, 1986; Sandelowski \& Jones, 1986). For the millions of women who experience a fertility problem, discussing this issue is an important concern that has the potential to influence social support, coping, and well-being (e.g., Gibson \& Myers, 2002; Mindes, Ingram, Kliewer, \& James, 2003). Women might experience social stigma (e.g., Whiteford \& Gonzalez, 1995), psychological distress (e.g., Abbey, 2000; Greil, 1997), and strained social interactions (e.g., Sandelowski \& Jones, 1986) associated with infertility. Women who experience distress might be compelled to disclose their fertility problem to vent and elicit social support. Alternatively, women who perceive others as unsupportive or fear social stigma might conceal the fertility problem. Studying privacy management in this context contributes to communication scholarship and raises awareness about a socially significant concern.

\section{Theoretical Assumptions}

Based on theoretically-derived propositions and grounded in empirical evidence, this essay is intended to draw greater attention to the discursive dynamics of communication phenomena like topic avoidance, disclosure, and secret-keeping, as well as the multiple meanings people ascribe to such interactions. Petronio’s CPM theory is one of the most widelyused theoretical resources for understanding privacy management processes. CPM employs a boundary metaphor to understand how individuals (and dyads and groups) control private information by creating boundaries around the information that vary in their level of permeability. These boundaries are managed through the creation of privacy rules, which can 
evolve and change over time. However, boundary management is not always a smooth process, and turbulence can occur when people misunderstand or mismanage privacy boundaries. In the following section, I explain three theoretical propositions that have informed my thinking about privacy and disclosure and discuss how these propositions are drawn from and build upon key assumptions of CPM.

\section{Disclosure and Avoidance as Fluid, Social Processes}

The first supposition is that disclosure is a fluid, social process in which both interactants enable or constrain the direction of the conversation. This assumption, based on tenets of CPM and research examining painful self-disclosure (Coupland et al., 1991), is consistent with calls to recognize communicative actions as negotiated processes that emerge between parties (Baxter \& Sahlstein, 2000).

CPM asserts that privacy management is a dynamic and ever-shifting process. According to the theory, contextual criteria such as changing life circumstances (e.g., a divorce) and elements of the social environment can prompt the revision or formulation of privacy rules. Likewise, boundary turbulence, in which the coordination of privacy boundaries fails, might also lead people to change the way they handle private information. CPM also recognizes the social nature of privacy management by asserting that disclosure is not just about the self and "that others are also central to discerning the tension between being public and private” (Petronio, 2002, p. 2). While the assumption driving the current study is entirely consistent with these tenets of CPM, I wish to advance theoretical thinking by shifting scholarly attention to the microlevel moment-to-moment interactions in which privacy processes unfold. Social actors are jointly responsible for the unfolding nature of any given interaction, and attention to discursive dynamics is critical to moving theorizing beyond a focus on the sovereign self (i.e., a focus on 
what occurs within the individual), and shifting attention to a social, dialogic self, centered on what occurs between individuals (Baxter \& Sahlstein, 2000).

In this vein, Coupland and colleagues (1991) used discourse analysis in their study of disclosure of painful circumstances (e.g., severe ill health) in intergenerational conversations between elderly women and young women. Their framework assumed that disclosure is a “complex social process” (p. 108) and focused on how both interactants in a conversation play a role in forming the conversational context in which disclosure (or avoidance) happens. They argued that what information is offered voluntarily and intentionally is not always clear. For instance, interactional partners can play a role in eliciting disclosive information and thus guide the emergent nature of the interaction. Their work, therefore, drew attention to how disclosive topics arise in conversation and how they are discussed. The current study seeks to extend this work by examining such processes across a variety of conversational contexts.

\section{Boundary Management Involves Variation in How People Disclose and Avoid}

The second theoretical assumption draws attention to the complex nature of managing privacy boundaries through the use of various messages. This assumption is also based on work by Petronio (2002) and Coupland and colleagues (1991). Although the focus of this study is not on boundaries per se, CPM's proposition that people develop boundaries provides a useful framework for understanding that disclosure and avoidance are not necessarily simple decisions

of whether to tell or not, but rather decisions of managing boundaries, of deciding who can know how much and with what stipulations.

Taking this CPM concept a step further, using Coupland and colleagues’ study of painful self-disclosure provides a useful framework for understanding the varied ways that people might discuss a particular circumstance (i.e., managing privacy boundaries by what they say or do). A 
disclosure message, for instance, might contain only the "core component” in which the speaker restricts herself "to the reporting or naming of the painful state or event and no more than this" (Coupland et al., 1991, p. 93). Thus, a core component message is an example of how someone might engage in a mixture of disclosure and avoidance simultaneously (see Afifi et.al, 2007) by revealing some aspects of a situation while avoiding the discussion of others. Alternatively, the core component message reporting the state or event might be coupled with additional information, such as background information or affective responses. Moreover, the discloser might elaborate on this additional information by giving a minimal level of detail or an immense level of detail. The current study builds on the boundary management assumption of CPM by drawing on the painful self-disclosure paradigm to understand how people talk or avoid talk across a variety of situations and to explore how interlocutors enable and constrain disclosure and avoidance.

\section{Disclosure and Avoidance Involve Multiple Meanings}

The final assumption that talking about or avoiding a particular topic involves multiple meanings is based on scholarship that draws our attention to the multiple, potentially conflicting, meanings associated with talk (e.g., Goldsmith, 2004; Goldsmith, Lindholm, \& Bute, 2006). According to this approach, talk is “meaningful social action” (Goldsmith, 2004, p. 50), and “communication is purposeful” (Caughlin, 2010, p. 826). This perspective suggests that there are many possible meanings associated with any given communicative act, and research using this approach to understand particular speech events (e.g., social support) has focused on the diverse meanings of interpersonal communication. In other words, meanings are not inherent to specific behaviors; rather, meanings result from interpretations of behaviors. The way people talk (or avoid talk) implies something about their efforts to manage these multiple meanings and reflects 
their interpretations of particular interactions, making this framework a promising approach to understanding how multiple meanings of talk can influence how people disclose and avoid and why it is possible to construct a range of different messages regarding the same piece of information (e.g., a fertility problem).

While CPM, acknowledges that people have a range of motivations that guide their privacy management decisions, the theory does not address the multiple meanings framework per se. I drew on this framework to build on tenets of CPM in this study by exploring multiple meanings as a potential trigger that can prompt people to change their privacy rules. Because the theory posits that privacy rules are malleable, I explored how the meanings associated with particular privacy management processes might activate rule creation or rule shifting in any particular conversational moment, a process consistent with by not explicitly addressed by CPM.

I used these theoretical assumptions to inform my understanding of the ways in which women discuss their infertility with others and to explore the following research questions:

RQ1: How do women describe interactions in which they manage private information about a fertility problem?

RQ2: What meanings do women attribute to their conversations about a fertility problem?

\section{Method}

\section{Participants}

After receiving Institutional Review Board approval, I recruited participants through advertisements in an electronic newsletter sent to faculty and staff at a large Midwestern university and through a process of snowball sampling. Women contacted me to express interest in the study and schedule a mutually convenient interview time. I arrived at a final sample of 23 after I started to notice recurrent themes in the interviews (Patton, 2002). 
Participants’ ages ranged from 28 to 48 years $(M=36.36$, $S D=4.99)$, and all were married at the time of the interview. Twenty of the women described themselves as Caucasian or white, one described herself as Jewish, one described herself as European, and one described herself as Hispanic. The majority of women in the sample were highly educated: fifteen had graduate degrees, and all had completed at least some college. Most of the women were employed by the university in occupations such as professor, administrative assistant, and librarian. Other women held professions such as teacher, dentist, and graphic designer.

Twenty-one of the women had received a medical diagnosis for infertility, including polycystic ovarian syndrome $(n=11)$, unexplained infertility $(n=3)$, age-related infertility $(n=$ $2)$, endometriosis $(n=2)$, and progesterone or thyroid problems $(n=2)$. Other diagnoses included anovulation, acidic cervical fluid, scarred fallopian tubes, anti-ovarian antibodies, and low ovarian reserve. Twenty-two women had sought medical treatment for infertility. At the time of the interview, eight women had never given birth and were not pregnant. Four women were pregnant at the time of their interview, three with their first child, and one with her second child. Twelve of the 23 women had at least one child; two women had adopted a child and ten had given birth (some of whom conceived with the assistance of medical intervention). Finally, three had experienced secondary infertility (i.e., trouble getting pregnant after giving birth).

\section{Data Collection}

In-depth interviews are an appropriate and useful method for studying talk about private information, especially in studies of highly sensitive topics for which ethical considerations impede researchers from directly observing or recording conversations (also see Keeley, 2004; Petronio, Reeder, Hecht, \& Ros-Mendoza, 1996). Observing conversations that involve disclosure of highly sensitive information poses a number of practical and ethical dilemmas (e.g., 
conducting observations to avoid exerting undue pressure on participants). And observations of avoidance are often impossible (i.e., an observer might not realize when an individual has intentionally avoided disclosure). Thus, communication scholars have found success in using retrospective accounts of conversations to study disclosure and avoidance of potentially stigmatizing information (e.g., Greene \& Faulkner, 2002). In-depth retrospective interviews also allowed me to ask questions about how women interpreted their conversations.

At the beginning of the interview, each woman completed a short demographic questionnaire. The interview guide included a series of questions concerning (a) to whom women had disclosed or not disclosed, (b) factors women considered when deciding whether to disclose, (c) details of disclosure and avoidance interactions, (d) responses women received when they disclosed, and (e) women's perceptions of interactions. Interview length ranged from 45 to 90 minutes, with an average length of 60 minutes. Interviews were recorded and transcribed verbatim.

\section{Data Analysis}

I used an iterative process (Strauss \& Corbin, 1990), for data analysis. First, I read each transcript to gain a holistic sense of the data. I wrote brief research memos to record preliminary impressions of the data. Based on these impressions and my research questions, I next completed a more systematic reading of all transcripts, concentrating on women's descriptions of specific conversations. Borrowing techniques from grounded theory, I conducted a constant comparative analysis (Strauss \& Corbin, 1990) of types of interactions, which resulted in categories and subcategories. For instance, I noticed that almost every woman I interviewed received requests for infertility-related information from others, so "requests for information” became an interaction- 
type category. After developing a set of categories, I then identified and developed dimensions that distinguish the categories from one another (e.g., Coupland et al., 1991; Goldsmith, 2000).

To test and refine the categories of types of interactions and to explore how women talked about infertility and the meanings associated with talking (or not), I made another pass through each transcript. I narrowed my unit of analysis to instances in which women described conversations where they revealed or avoided revealing aspects of their fertility problem to people in their social network. These interactions included examples of the initial telling, in which a person goes from not knowing to knowing about a women’s infertility, as well as cases involving partial telling (e.g., a woman reveals trouble getting pregnant but does not discuss any further details), ongoing telling (e.g., revealing additional aspects of the fertility problem over time), or avoidance of telling (e.g., not telling others about treatments sought for infertility). For each interaction (i.e., unit of analysis) I determined (a) how the topic came up, (b) how the topic was discussed (or not), and (c) the meanings women associated with talking or not talking. Based on this analysis, I refined and clarified the types of interactions categories and used constant comparison to create categories of how women talked (e.g., direct or indirect) and the meanings and dilemmas associated with talk.

I ensured the trustworthiness of my claims by producing an audit trail (Farley \& McLafferty, 2003), including theoretical notes and memos. These documents, and the interview recordings and transcripts, provide a history of my methodological and theoretical decisions.

\section{Results}

Drawing on interviews with women, I offer in-depth descriptions of women's conversations about infertility. More specifically, results indicated wide variation in how a topic 
arose in conversation, how women revealed and concealed a fertility problem, and the dilemmas women faced in such conversations.

\section{How a Topic Comes Up in Conversation}

Based on the assumption that disclosure and avoidance are fluid, social processes, one key element to which scholars must attend is the way particular topics arise in conversations. As Coupland and colleagues (1991) noted, self-disclosure is a complex social process that unfolds during real-time interactions. In the following section, I illuminate some of the conversational dynamics involved in disclosing or avoiding discussion of a fertility problem by delineating a typology of various interactions. My analysis suggested three major categories of interactions: (a) discloser initiated disclosures, (b) routine interactions, and (c) recipient requests for information (see Table 1).

Discloser initiated disclosures. Discloser initiated disclosures include examples such as conversations in which women either instigated a conversation in order to discuss their fertility problem or initiated talk about infertility and associated topics during a particular conversation. For example, when people think of disclosing a serious condition such as a fertility problem to intimate others, they might think of a carefully planned conversation, or big talk, in which the discloser has considered ahead of time when and how to discuss the topic (Greene et al., 2003). Indeed, some women described situations in which they consciously planned the first disclosure of their fertility problem. Anna recalled in extensive detail the first time she and her husband revealed their fertility problem to her parents:

They live a little over three hours away, and we didn’t want to start this conversation over the phone. We really wanted it to be in person, and we really wanted the four of us to be together. And so we went to visit them and didn’t tell them ahead of time, “Hey there’s 
something we wanna talk to you about.” We all went in the living room and sat down and I think I had brought some articles that we had already started reading. And we kind of went through the process and everything we had done up to that point and everything that we had found out through the doctor and what we thought we might do. So that was much more planned out.

This conversation was not prompted by a particular event or circumstance, just Anna’s desire to tell her parents in person rather than over the phone.

In some cases, talk was prompted by a turning point related to the fertility problem, such as a medical diagnosis, or a specific obligation, such as accounting for absences at work. Many women cited seeking medical treatment as a circumstance that prompted them to reveal their fertility problem for the first time. Linda and her husband waited to tell her husband's mother until they underwent testing to identify the source of their problem. She explained, "When we finally reached the one-year mark, we told her that we were going in for counseling and that we were both going to be tested to see if there was anything wrong.” For some women with a fertility problem, an unfortunate circumstance compelled them to reveal their condition. Some women in this sample announced a pregnancy to friends and family and then experienced a miscarriage, obliging them to share this bad news with their social network. Nancy had experienced a health scare that turned out to be a pregnancy. She shared this joyful news with friends and relatives who were relieved that she was not seriously ill and thrilled about the prospect of a baby; however, after she had a miscarriage, Nancy and her husband had to tell people about their situation: 
One of the hardest things was trying to track down all the people that we told about the pregnancy, 'cause we were so relieved after this scare, and trying to track all these people down and say, “Oh, well the pregnancy’s over.”

Although a variety of circumstances can trigger the revelation of a fertility problem, women in each of these situations initiated discussion of the fertility problem during the conversation.

Routine interactions. In contrast to discloser-initiated interactions, the routine interactions category is best exemplified by ongoing, everyday conversations in which the textual momentum of the conversation, rather than an a priori desire to disclose a particular turning point or circumstance, compelled women to disclose or actively avoid disclosing. Erica, like other women in the sample, interpreted general inquiries as an appropriate opportunity to engage in ongoing disclosure about the fertility problem. "For example, at family gatherings, people might say, 'What's going on? What's new in your life?’” Erica explained, “And then I'll just take that as an opportunity to just say, 'Well, you know, you probably knew that we were having problems, and here's what's, here's the next step that they've taken to figure out what's going on.'” General inquiries can be interpreted as tacit permission to divulge a fertility problem for the first time and as a means of engaging in ongoing talk about the topic.

Women also described disclosing a fertility problem during everyday interactions when topical relevance provided a suitable textual moment. Marcia recalled revealing her fertility problem in response to a comment made during an everyday interaction with her mother:

And she brought up, she brought up the subject, something or other of grandkids or something like that, and not in a nagging sort of sense, but just, you know, when it happens or whatever, and this or that or the other thing. I can't remember where she was going with the conversation, but I thought, “Well, I ought to tell her”. And so I did. 
Topical relevance sometimes came in the form of reciprocation when women responded to one person's disclosure of infertility by revealing their own infertility. In sum, the textual context created by either discussion of topics related to childbearing or by one person's disclosure made a revelation by the other party textually relevant and appropriate. In these situations, it was clear that women did not approach conversations with a pre-formulated intent to disclose that they arrived at the decision after conducting a careful mental calculus weighing potential risks and benefit. Rather, the momentum of the conversation itself prompted revelations; a phenomenon that illustrates the dialogic, emergent processes at play in privacy management interactions.

Requests for information. Women described situations in which social network members directly or indirectly requested information about childbearing, pregnancy, and infertility (e.g., when are you going to have children?) that prompted disclosure or avoidance (also see Bute, 2009 for a detailed discussion of these requests). Women described conversations in which people asked them direct questions about their plans to have children, inquired as to whether or not they were currently pregnant, or in some instances, asked pointed questions such as whether a woman or her husband was to blame for the fertility problem or whether a woman had considered adoption. In every interaction included in this category, others' attempts to elicit information prompted women to make a decision about whether and how to respond to a request for information (e.g., should I reveal my fertility problem? should I share details regarding treatment and adoption decisions?).

In addition to identifying three major types of interactions in which topics arise, Table 1 also summarizes four dimensions that differentiate the interactions. First, interactions vary according to who or what initially prompted discussion or avoidance of the topic: the potential discloser (i.e., in this case the woman with the fertility problem), the textual momentum of the 
conversation (e.g., discussion of fertility-related topics at a baby shower, reciprocation of another's disclosure), or the potential recipient (e.g., a person asks about childbearing plans). Interactions also vary in the degree to which the role of the potential discloser is constrained by the conversational context. I found that potential discloser's roles are most constrained when people solicit information from them, compelling them to make decisions about whether and how to tell (Bute, 2009; Coupland et al., 1991) and, potentially, threatening their control of this sensitive information (Petronio, 2002). Because discloser initiated interactions and routine interactions typically, though not always, involve intimate others or coworkers, these interactions often entail a greater social or relational obligation to tell than do requests for information. Finally, interactions might be part of ongoing talk in the sense that additional disclosures can occur across a series of conversations. This idea is perhaps illustrated most clearly in the case of certain routine interactions in which people engage in ongoing disclosure or avoidance with a confidant over time. For instance, Anna described an ongoing pattern of topic avoidance during regular conversations with her former college roommate. Whenever her friend inquired about Anna's plans to have children, she would actively avoid disclosing her fertility problem by making excuses, such as being overwhelmed at work. Delineation of these dimensions illuminates the many and varied ways that people engage in disclosure and avoid particular topics and highlights the conversational dynamics and relational complexities involved in deciding whether to divulge aspects of private information. The following section elaborates how topics are discussed or avoided when they arise in conversation.

\section{How a Topic is Discussed or Avoided}

Based on the assumption that managing privacy boundaries (Petronio, 2002) is part of a complicated process and Coupland and colleagues’ (1991) work on painful self-disclosure, my 
analysis suggests the various factors that can affect the manner in which topics are discussed or avoided. A disclosure message, for instance, might contain only the core component or might include the core component plus additional details (e.g., thoughts and feelings, information about medical diagnosis and treatment). The amount of detail shared can range from a minimal level to an enormous level of detail. Sometimes women disclosed a fertility problem in a direct way, and other times women used more indirect messages that hinted at their difficulty getting pregnant.

Women described conversations in which they directly and explicitly disclosed aspects of their fertility problem to others. First, women described disclosures involving only the core component of the state or event with no additional detail added. When discussing in her interview how she responded to inquiries about having a second child, Lisa said, "I just tell them that we had a hard time conceiving, and we're not going to have another one.”

Sometimes women added a minimal amount of detail to the core message reporting their circumstance but did not delve into all the possible associated topics surrounding the fertility problem. When Andrea would tell people about her fertility problem she would typically say something like, “Well, you know, we’ve been trying for a year and a half now and we haven’t had any luck, but we're going to go ahead and get some tests done.” Notice how this message reveals not only the fertility problem but also the fact that Andrea and her husband planned to seek medical assistance.

In some cases, women disclosed additional information in response to inquiries from the recipient in a particular conversation or discussed additional aspects over a series of conversations. The additional information divulged sometimes included only a minimal amount of detail and sometimes included extensive detail and discussion of issues related to infertility, including treatment options and decisions and emotional aspects of the experience. Sometimes 
discussion of infertility began with an initial disclosure and continued with ongoing updates as certain milestones occurred (e.g., trying a new treatment, deciding to adopt a child). For instance, when Anna described in her interview what she shares and doesn't share with her brother, she said, "He gets the big stuff. He doesn’t always get the day-to-day."

In fact, women often communicated during their interviews intentional decisions to share only selective details with particular people. Cheryl kept her mother updated about treatment procedures and outcomes but stopped short of discussing “intimate interactions” with her husband. Erica described sharing "the whole gory detail” of the medical procedures she underwent during testing and treatment for her fertility problem when she talked to her grandmother but did not feel comfortable discussing emotional aspects of the experience.

In other cases, women discussed their fertility problem and associated aspects in extensive detail. Marissa and her best friend talked about a wide range of topics. Marissa not only updated her friend on medical appointments and treatment outcomes, she also discussed emotional concerns, such as her thoughts about the moral and ethical issues surrounding treatments for infertility, including selective abortion in the event of multiple embryos.

Women recalled instances in which they hinted to others that they had a fertility problem by giving vague or indirect answers to questions. Such messages hinted at the core component of the state or event. Several women commented on their intentional choice to divulge their fertility problem in a discreet way, leaving the listener to draw his or her own conclusions. Stacy, who was trying to get pregnant with her second child at the time of her interview, explained how she handled questions about having another child: 
People say, “When are you going to have it?” and it’s like, “We’re trying. We'd like to have baby number two. We're trying. Just don’t know if it’s going to happen.” I say, “Don’t know if it’s going to happen.” And I think that they can conclude from that. Notice how Stacy’s final comment implies that the recipient can likely conclude from her indirect response that she is having trouble getting pregnant.

Women also used various strategies to evade disclosing aspects of their fertility problem to others. Sometimes women responded to inquiries with direct messages, including lies or accounts that allowed them to avoid disclosure of their fertility problem. Such messages explicitly answered a question about childbearing or infertility without actually revealing the fertility problem itself. Sharon reported frankly denying the fact that she had undergone treatment for infertility when asked rather bluntly by a coworker if she had "help” conceiving. Anna chose not to disclose her fertility problem to her former college roommate and instead created excuses for not having children, such as being busy at work or moving into a new home, or intentionally changed the topic when her friend asked if she was pregnant yet.

Other women used more indirect messages to respond to queries. Such messages involved answering queries in a manner that enabled deflection of the topic and avoidance of a revelation. Kelly and other women in the sample regularly gave vague but "true” responses that allowed them to avoid revealing their infertility when they received questions about her plans to have children. Kelly would typically respond to queries by saying something like, “In God’s time” or “We'll see.” Women also reported using humor or sarcasm as a shield that allowed them to respond to queries without disclosing the fertility problem. Andrea, for instance, would joke that she already had two dogs at home when people inquired about her plans to have children. In her interview, Andrea described using this response to try to "lighten" the situation. 
Strategies to avoid disclosure did not always happen in response to inquiries. Some women, for example, took steps to avoid particular people or situations so that they did not have to discuss the fertility problem. Brenda, for instance, took careful steps to schedule her treatments on vacations or work holidays so that she could avoid potential discussions of why she had to miss work in the first place.

\section{Multiple Meanings of Talk: The Dual-Edged Sword}

Just as topics arose in conversations in various ways and were discussed or avoided in numerous ways, women also attributed multiple, potentially conflicting, meanings to talking or not talking about private information. Varied meanings of talk draw our attention to the challenges speakers face in their efforts to balance a particular communicative task (such as disclosing or avoiding talk) with other valued purposes, including identity and relational qualities (e.g., disclosing a fertility problem means revealing a potentially stigmatizing condition and possibly making the confidant uncomfortable, but not telling means not being "honest”). Andrea, characterized talking or not talking as a "dual-edged sword:” either decision has the potential to pose dilemmas. More specifically, the dual-edged sword metaphor highlights the identity, social support, and privacy control dilemmas that women managed as they made meaning of their interactions about infertility.

Identity dilemmas. Identity meanings of talk reflected efforts to present or defend a desired image of the self. As evidenced in previous work on meanings and dilemmas (Goldsmith et al., 2006), identity concerns were paramount for women in this study. Their descriptions of conversations regarding infertility clearly reflected efforts to manage how others viewed them (e.g., concerns with appearing honest, not stigmatized, and as wanting children). Both revealing and concealing a fertility problem can have important identity implications. On the one hand, 
talking about infertility allowed women to present themselves as honest people who are involuntarily childless rather than childless by choice. On the other hand, concealing the fertility problem allowed women to keep a potentially stigmatizing condition a secret.

Women described the decision to reveal their fertility problem, even in an indirect way (e.g., “We're still working on it”), as “honest,” “forthcoming,” “straightforward,” “truthful,” "upfront,” and “coming clean.” Some women who had concealed the fertility problem from certain others felt uncomfortable because doing so felt like "lying” or "not telling the whole truth.” Revelation of a fertility problem helped some women preserve an identity as someone who is honest. Revealing a fertility problem was also a means of preserving other valued identities. Lisa, who had given birth after successful medical interventions, described a situation in which someone asked her explicitly about her childbearing plans and labeled her as selfish for not wanting to have more than one child:

[The person asked Lisa] "When are you going to have another one?” “Well, I’m probably not going to.” She goes, “Well, that’s just mean.” And finally I looked at her and I said, "You know what? I had to give myself shots in the stomach. [Son’s name] is a blessing, and he’s going to be an only child.” She was like, “Oh. Okay.” But I think for a long time, I kept it secret... But now I’ve decided, you know what? I don’t care who knows, because I'm tired of people asking me, "When are you going to have another one? Why aren’t you going to have another one?” I’m like, “All right, I will tell you why I’m not going to have another one, truthfully.”

Lisa revealed her infertility by explaining that her decision not to have a second child was related to her experience with fertility problems and not to her identity as someone “mean.” In other words, Lisa revealed her fertility problem, in part, to salvage her identity. 
For some women, revealing to others that they were "trying" to get pregnant not only preserved an identity as someone who wants children, as opposed to someone who is voluntarily childless, but also let people know that they were trying to live up to family societal expectations for having children. As Amber put it, telling her parents that she was seeking treatment for infertility meant saying, "We're trying to provide you with grandchildren."

While talking about infertility was a means of preserving or projecting particular identities, not talking about a fertility problem was also a way of protecting identity. Cheryl was embarrassed to reveal her fertility problem because she associated the ability to get pregnant with her role as a woman. She said, “And we didn’t even tell anybody, or I didn’t tell my family for a while, just 'cause there is a little bit of an embarrassment aspect to it, I guess.” Admitting to others the inability to get pregnant or carry a child to term can amplify feelings of failure and the subsequent identity threat posed by infertility. In summary, revealing a fertility problem meant divulging a potentially stigmatizing condition and coming to terms with a perceived failure by admitting an inability to get pregnant, yet in some situations, the revelation was also a means of preserving other valued aspects of identity (e.g., as someone who is honest, as someone who is not selfish or mean). Both concealing and revealing pose tradeoffs_-do I risk revealing a failure and the judgment that could accompany that admission? If I don't admit infertility, what will others assume about my childless state? Such identity dilemmas were salient for women in this study.

Social support dilemmas. In addition to potentially dilemmatic meanings associated with identity, women also reported meanings related to social support. In some cases, women were able to elicit support or provide support to others through discussing infertility. However, 
divulging such a highly personal and sensitive issue also created burdens to educate people and awkward conversational moments as confidants struggled to express their support.

Many women found friends and family who provided ongoing support as they struggled with infertility. After telling her extended family about her fertility treatments, Erica found her grandmother to be a reassuring presence, especially after her grandmother revealed that others in the family had struggled to get pregnant. "I liked the thought that, you know, there’s other people in the family that had the same problem,” Erica explained. “You don't feel like you're the only one, you're some freak of the family, black sheep, you know.”

Disclosing a fertility problem also meant a chance to educate people about infertility, and in some cases provide support to others. Sharon, who struggled for years before conceiving and giving birth said, "If somebody approached me and said they were having problems, I would probably have no hesitation in telling.” Although many women took pleasure in and likely benefited from the chance to share their experience with other people, especially women experiencing infertility, some women found the need to educate others burdensome. Leah often found herself frustrated by the need to educate others:

My mother kept saying, “Oh, it’s that dancing, that dancing.” And it was her naiveté, but when you're a young, dancer, athlete, sometimes you don’t get your period for a while. You have less fat. And that happened to me a couple times in my youth. And she has this in her mind, “Oh, my God, that’s why you're not getting pregnant.” And I say, “No, it’s really not. I've got plenty of dancer friends who are having children. It's really not that.” And she couldn't get that out of her mind. Like, having the responsibility of educating other people about our situation was so burdensome. Because people question you, and want to give advice as soon as you say you're having infertility problems. “Oh, you need 
to stop coffee. Stop caffeine.” Somebody else says, “Oh, you’re not getting enough sleep.” Somebody else says, “You need to eat more.” Everybody has some old wives’ tale thing.

Leah’s situation also highlights one aspect of the dual-edged sword of support: the risk of unhelpful support. While the chance to elicit support and educate others about infertility was an affirming experience for some women, the burden of dealing with others' ignorance was also tiresome for some. And attempts at support were not always helpful or forthcoming. As Andrea explained, sometimes women did not get the support they expected:

But the other problem that, or the other situation is when you do tell people, you expect to get a certain amount of support and understanding. And so when people do know, like certain members of my husband’s family, and on occasion, even my own family, and certain, you know, whoever, if they do know and you still don't get that support, then it’s even more hurtful because they know and they're still insensitive about it.

Some women described protecting themselves from unhelpful support by not disclosing their fertility problem. Cara did not want suggestions and sympathy from others:

I don’t want sympathy and I don’t want to hear, “It’ll be okay,” you know, very degrading, in a way. And not meaning to, especially my family. I actually hadn't told my family until this last month, just because I didn’t want to receive boatloads of email research on methods that can be done for infertility. And, I hope this isn't too crass, my mother-in-law, I haven’t told her, but her suggestion, ‘cause she really wants a grandkid, is after copulating, stand on your head, you know, these great wives' tales. I just don’t need, some people really, really enjoy that conversational style... and I don’t find them comforting, I don't find them reassuring. 
One reason that confidants might have struggled to offer support in this context is that talking about infertility can mean discussing an uncomfortable topic and a painful experience. When women chose to talk about their situation, the discussion of infertility often involved either implicit or explicit references to sexual intercourse, reproduction, and basic bodily functions (e.g., menstruation), topics that Julie referred to as "private behavior that people feel like you shouldn’t be talking about.” Nancy commented on the awkwardness of disclosing her fertility problem, not only for herself, but also for recipients of the information:

And I felt like when I did tell people that I'd had a miscarriage, they didn't have the tools to respond. And they, they did things like, they tried to say nice things like, "Well it wasn’t meant to be” or “Oh, you can have another one” or whatever. But there was a lack of a common, I don’t know, a common linguistic base for it. Or a common, just a way of talking about it where people didn’t feel extremely uncomfortable. There were times that I was telling people that I'd miscarried, and I sensed that they were more uncomfortable with it, with the information, than I was. It was hard for me to tell them, but it was even harder for people to hear it.

In sum, talking or not presented a dual-edged sword in that concealing a fertility problem could mean missing out on the chance to elicit social support. On the other hand, even when women revealed a fertility problem, support from others was sometimes unhelpful, insensitive, or even absent. Some interactions offered an opportunity for women to seek support and reassurance or to share their knowledge with others in need, but in some cases the constant necessity to educate others about myths surrounding infertility became a burden.

Privacy control dilemmas. Finally, decisions regarding whether and how to talk about infertility offered some women a means of control or information management in the midst of an 
uncertain and often chaotic life event. However, that sense of control was often threatened by incessant questions from others.

In some situations, decisions to conceal or reveal meant that women could develop privacy rules and monitor who had access to this information, and also influence or prevent future interactions. As Anna explained, “And that, that control, I think, we've lost so much of it through this whole thing that we have chosen to control it by sharing it with people or not sharing it with people.” Linda’s fear of becoming the topic of workplace gossip influenced her decision not to discuss her fertility problem in the office, and some women simply expressed that they did not want particular others to have this information.

As women sought to maintain their privacy, requests for information were sometimes a threat to the control of sensitive information (also see Table 1). In fact, Andrea described these questions as one risk of choosing not to disclose a fertility problem:

And that's the one thing, it's kind of a dual-edged sword. [emphasis added] Where when you don't tell people, whether they be family or whoever, you do get the "When are you going to have kids? When are you going to have kids?” And for some reason, I don’t know why, it seems to be an okay thing to ask people that. But if you think about it, it's like one of the most personal questions you could probably ever really ask somebody... So you have that problem if you don't tell people, in that they're going to ask you questions. For some reason, they think it’s okay, and they will. In general, direct requests for information or explicit questions from non-intimate others (i.e., those without close relational ties) were interpreted by the women in this sample as invasions of privacy. Women also described some questions from intimates as “nosy” or “rude.” In light of CPM's assumption that people feel a right to control personal information, it makes sense that 
women might feel threatened or offended by the solicitation of information, especially from those with whom they do not share close relational ties. Many women expressed disbelief at others’ willingness to ask “personal” and “private” questions about childbearing, pregnancy, and infertility. So, while the choice to manage private information in particular ways can afford women a sense of control while they cope with unpredictable circumstances, women also described privacy dilemmas that highlighted how control can be threatened by requests for information. Moreover, people might be more likely to ask invasive questions if they are unaware of the fertility problem.

The analysis of meanings reveals the array of dilemmas women faced as they managed identity concerns, elicitation and provision of social support, and the information itself. Concealing a fertility problem can mean a sense of control because women can decide who has access to the information (Petronio, 2002); however, keeping a secret can mean feeling dishonest, as though one is lying by omission. Not talking about infertility can be a means of protecting the self from insensitive comments and unhelpful support, but women are still asked to account for their childless state and might have to contend with ongoing questions about when they plan to have children or why they do not currently have children.

\section{Discussion and Implications}

Although a rich literature addresses privacy-related topics, comparatively few studies illuminate interactional manifestations of privacy management (Baxter \& Sahlstein, 2000). Results of this study extend our understanding of conversational dynamics by exploring in detail how a topic arises in conversation, the meanings attributed to talk, and the dilemmas people face when deciding whether to discuss or avoid a particular topic. 
The results of this study serve a key theoretical function in moving scholars beyond the conceptualization of disclosure and avoidance as two categories in a bivariate construct (Afifi et al., 2007). For instance, thoughtful attention to how a topic is discussed or avoided supports Afifi and colleagues' contention that disclosure and avoidance are not straightforward opposites and that "sometimes people can address a single topic with a mixture of avoidance and discussion" (p. 84). We see several illustrations from women's stories that mix disclosure and avoidance in a single message (e.g., disclosing medical treatments for infertility but intentionally avoiding discussion of the emotional toll of treatments). The results complement tenets of Petronio’s CPM by offering tools for exploring how the complex process of boundary management unfolds in particular conversations. For instance, we can see how the content of a particular message (e.g., whether the message contains only the core component or whether the message includes additional details) illustrates effort to manage boundary permeability. Conveying minimal information can mean that a boundary is thicker and less permeable, while divulging extensive information means that the boundary is more permeable. In this sense, boundary management consists of much more than a "to tell or not to tell" decision.

Results of this study also suggest the key role that both interactants play in shaping whether and how a person conceals or reveals private information. The analysis of how various topics arise in conversations suggests that the conversational constraints placed on potential disclosers can vary according to whether they initiated talk about the topic, whether talk was prompted by the textual context, or whether potential recipients requested disclosive information. This typology (Table 1) expands Coupland and colleagues (1991) work on painful self-disclosure in important ways. First, it is intended for application to a variety of interactions, including interactions with strangers, acquaintances, friends, and relatives. In contrast, Coupland et. al 
focused on an isolated conversational circumstance: researcher prompted first acquaintance conversations between elderly women and young women. The proposed typology of types of interactions also provides tools for examining a variety of conversations, including routine, everyday conversations during which people discuss (or avoid discussing) a certain issue, such as their fertility problem, with others. Finally, the typology reveals the enormous variation in talk about just one particular issue, in this case a fertility problem, as evidenced by the variations in how women disclose or avoid.

Results of the study build on concepts of CPM by pushing the notion of privacy management as a social process to a more micro-level of attention. CPM offers outstanding tools for thinking about social processes in its assumptions about the coordination and negotiation of privacy boundaries that occurs between parties. CPM allows us to understand decisions about granting and denying access but offers comparatively fewer tools for understanding discourse and conversational dynamics. The present study attempts to emphasize conversational dynamics and to consider how both parties enable and constrain what is said, whether the topic comes up in the first place, and so on. This idea is perhaps most apparent in instances when people request disclosive information from women and thus restrict the interaction in the sense that women must choose how to manage these requests.

Finally, by attending to multiple meanings of talk, we can begin to explore the potential consequences of how disclosure and avoidance unfold in interactions. As Afifi and colleagues (2007) noted,

Although it is not particularly controversial in the field of communication to claim that the way one engages in a particular type of tactic matters, this manner of thinking is a departure from almost all research on avoidance, secret keeping, and disclosure (p. 84). 
Considering multiple meanings of talk provides one tool for thinking about that various ways people avoid and disclose certain topics and how the way we engage in disclosure or topic avoidance make a difference. For instance, if someone interprets a woman’s response to an inquiry such as “Do you have children?” as invasive or rude, that interpretation has consequences that could affect whether that individual broaches the topic in future interactions. On the other hand, the way the question was posed, could influence a woman's interpretation of the question and thus affect whether and how she discloses a fertility problem. And whether and how a woman discloses in any given conversation could influence her access to social support. Imagine a verbal message in which the disclosure explicitly requests social support (e.g., "I’m having trouble getting pregnant, and I really need someone to talk to about this.”) versus an indirect message. It would be difficult, though certainly not impossible, for a confidant to ignore an explicit request for support; however, in the case of an indirect message (e.g., "We're trying to get pregnant”) the intended target might not even realize that a disclosure was made let alone realize that the discloser might need support or comfort. Moreover, the range of messages a particular person might use to discuss the same piece of information reflects efforts to manage multiple purposes and deal with multiple meanings of talk. I found Goldsmith's (2004) work on multiple meanings and especially appropriate framework for understanding how women make sense of conversations and how these meanings influence talk (e.g., if a woman interprets an inquiry as threatening a desire to present herself as someone who wants children, she might reveal her fertility problem to that person, even if the inquiry was annoying or invasive).

The multiple meanings framework also builds on assumptions of CPM (Petronio, 2002). The attribution of certain meanings in moments of interaction can be viewed as a particular sort of trigger that can motivate people to create or revise their handling of private information. 
Novel situations, such as highly memorable conversations, can result in changing privacy rules that might carry into future interactions. Some women, for example, discussed strong emotional reactions to inquiries about their childlessness that prompted them to divulge what had previously been kept secret. And sometimes, women created a new privacy rule in which they started revealing their fertility problem in the face of seemingly incessant questions.

\section{Considerations for Future Research}

The categories suggested in this study are intended as tools for understanding the complex discursive dynamics involved in topic avoidance and disclosure and would benefit from additional application and refinement to explore whether and how a complex interrelationship exists among the categories. For instance, it might be that some ways of introducing the topic are more often associated with certain types of talk or with certain meanings. Results of my study, for instance, seem to imply that some ways of broaching a topic are more likely to result in certain ways of discussing a topic. Specifically, recipient requests for information described by women in this study were frequently met with indirect disclosures or with efforts to actively avoid disclosure of the fertility problem, especially when these inquiries meant that the asker was being insensitive or invading a women's privacy. Additional studies in other contexts could seek to detect other patterns. Although the phenomenon of requests for information was highly relevant to women in this study, this might not be the case in other contexts where inquiring about a certain topic is not already part of a socially accepted interaction ritual. The particular meanings that are relevant will also vary from one context to another since meanings are not inherent to particular behaviors (Caughlin, 2010; Goldsmith 2004). All in all, this essay paves the way for scholars of communication to continue investigating talk about private information. 


\section{References}

Abbey, A. (2000). Adjusting to infertility. In J. H. Harvey \& E. D. Miller (Eds.), Loss and trauma: General and close relationship perspectives (pp. 331-341). Philadelphia: Brunner-Routledge.

Afifi, T. D., Caughlin, J. P., \& Afifi, W. A. (2007). The dark side (and light side) of avoidance and secrets. In B. H. Spitzberg \& W. R. Cupach (Eds.), The dark side of interpersonal communication (2nd ed.), (pp. 61-92). Mahwah, NJ: Erlbaum.

Afifi, T. D., \& Steuber, K. (2009). The revelation risk model (RRM): Factors that predict the revlation of secrets and the strategies used to reveal them. Communication Monographs, 76, 144-176. doi:10.1080/03637750902828412

Altman, I., \& Taylor, D. A. (1973). Social penetration: The development of interpersonal relationships. New York: Holt, Rinehart, \&Winston.

Baxter, L. A., \& Sahlstein, E. M. (2000). Some possible directions for future research. In S. Petronio (Ed.), Balancing the secrets of private disclosures (pp. 289-302). Mahwah, NJ: Erlbaum.

Ben-Ari, A. (1995a). Coming out: A dialectic of intimacy and privacy. Families in Society, 76, 306-314.

Ben-Ari, A. (1995b). The discovery that an offspring is gay: Parents', gay men's, and lesbians' perspectives. Journal of Homosexuality, 30, 89-112. doi:10.1300/J082v30n01_05

Bute, J. J. (2009). “Nobody thinks twice about asking:” Women with a fertility problem and requests for information. Health Communication, 24, 752-763.

doi:10.1080/10410230903265920 
Caughlin, J. P. (2010). A multiple goals theory of personal relationships: Conceptual integration and program overview. Journal of Social and Personal Relationships, 27, 824-848. doi:10.1177/0265407510373262

Caughlin, J. P., Brashers, D. E., Ramey, M. E., Kosenko, K. A., Donovan-Kicken, E., \& Bute, J. J. (2008). The message design logics of responses to HIV disclosures. Human Communication Research, 34, 655-684. doi:10.1111/j.1468-2958.2008.00336.x

Caughlin, J. P., Bute, J. J., Donovan-Kicken, E., Kosenko, K. A., Ramey, M. E., \& Brashers, D. E. (2009). Do message features influence reactions to HIV disclosures? A mutliple-goals perspective. Helath Communication, 24, 270-283. doi:10.1080/10410230902806070

Coupland, N., Coupland, J., \& Giles, H. (1991). Language, society, and the elderly: Discourse, identity, and ageing. Oxford, UK: Blackwell.

Derlega, V. J., Metts, S., Petronio, S., \& Margulis, S. T. (1993). Self-disclosure. Newbury Park, CA: Sage.

Farley, A., \& McLafferty, E. (2003). An introduction to qualitative research concepts for nurses. Professional Nurse, 19, 159-163.

Figueiredo, M. I., Fries, E., \& Ingram, K. M. (2004). The role of disclosure patterns and unsupportive interaction in the well-being of breast cancer patients. Psycho-Oncology, 13, 96-105. doi:10.1002/pon.717

Gibson, D. M., \& Myers, J. E. (2002). The effect of social coping resources and growth-fostering relationships on infertility stress in women. Journal of Mental Health Counseling, 24, 6880.

Goldsmith, D. J. (2000). Soliciting advice: The role of sequential placement in mitigating face threat. Communication Monographs, 67, 1-19. doi:10.1080/03637750009376492 
Goldsmith, D. J. (2004). Communicating social support. Cambridge: Cambridge University Press.

Goldsmith, D.J., Lindholm, K.A., \& Bute, J.J., (2006). Dilemmas of talking about lifestyle changes among couples coping with a cardiac event. Social Science and Medicine, 63, 2079-2090. doi:10.1016/j.socscimed.2006.05.005

Greene, K., Derlega, V. J., Yep, G. A., \& Petronio, S. (2003). Privacy and disclosure of HIV in interpersonal relationships. Mahwah, NJ: Erlbaum.

Greene, K., \& Faulkner, S. L. (2002). Expected versus actual responses to disclosure in relationships of HIV-positive African American adolescent females. Communication Studies, 53, 297-317. doi:10.1080/10510970209388595

Greil, A. L. (1997). Infertility and psychological distress: A critical review of the literature. Social Science and Medicine, 45, 1679-1704. doi:10.1016/S0277-9536(97)00102-0

Keeley, M. (2004). Final conversations: Messages of love. Qualitative Research Reports in Communication, 5, 34-40.

Miall, C. E. (1986). The stigma of involuntary childlessness. Social Problems, 33, 268-282. doi:10.1525/sp.1986.33.4.03a00020

Mindes, E. J., Ingram, K. M., Kliewer, W., \& James, C. A. (2003). Longitudinal analyses of the relationship between unsupportive social interactions and psychological adjustment among women with fertility problems. Social Science and Medicine, 56, 2165-2180. doi:10.1016/S0277-9536(02)00221-6

Patton, M. Q. (2002). Qualitative research and evaluation methods (3rd ed.). Thousand Oaks, CA: Sage. 
Petronio, S. (2002). Boundaries of privacy: Dialectics of disclosure. Albany, NY: State University of New York Press.

Petronio, S., Reeder, H. M., Hecht, M. L., \& Ros-Mendoza, T. M. t. (1996). Disclosure of sexual abuse by children and adolescents. Journal of Applied Communication Research, 24, 181-199. doi:10.1080/00909889609365450

Sandelowski, M., \& Jones, L. C. (1986). Social exchanges of infertile women. Issues in Mental Health Nursing, 8, 173-189. doi:10.3109/01612848609014564

Silver, R. C., Wortman, C. B., \& Crofton, C. (1990). The role of coping in support provision: The self-presentational dilemma of victims of life crises. In B. R. Sarason \& I. G. Sarason (Eds.), Social support: An interactional view (pp. 397-426). New York: Wiley.

Strauss, A., \& Corbin, J. (1990). Basics of qualitative research: Grounded theory procedures and techniques. Newbury Park, CA: Sage.

Whiteford, L. M., \& Gonzalez, L. (1995). Stigma: The hidden burden of infertility. Social Science and Medicine, 40, 27-36. doi:10.1016/0277-9536(94)00124-C 
Table 1

Ways Infertility and Related Topics Come Up in Conversation

\begin{tabular}{|c|c|c|c|c|}
\hline $\begin{array}{c}\text { Interaction } \\
\text { Type }\end{array}$ & $\begin{array}{c}\text { Disclosure or } \\
\text { Avoidance Prompted } \\
\text { by Potential Discloser, } \\
\text { Textual Context, or } \\
\text { Potential Recipient }\end{array}$ & $\begin{array}{l}\text { Level of Constraint } \\
\text { Imposed on the } \\
\text { Potential Discloser } \\
\text { by the } \\
\text { Conversational } \\
\text { Context }\end{array}$ & $\begin{array}{l}\text { Social or } \\
\text { Relational } \\
\text { Obligation to } \\
\text { Tell Exists }\end{array}$ & $\begin{array}{l}\text { Part of } \\
\text { Ongoing } \\
\text { Talk } \\
\text { About the } \\
\text { Topic }\end{array}$ \\
\hline $\begin{array}{l}\text { Discloser } \\
\text { Initiated }\end{array}$ & Potential Discloser & Low & Often & Sometimes \\
\hline $\begin{array}{c}\text { Routine } \\
\text { Interactions }\end{array}$ & Textual Context & Medium & Often & Often \\
\hline $\begin{array}{l}\text { Recipient } \\
\text { Requests for } \\
\text { Information }\end{array}$ & Potential Recipient & High & Sometimes & Sometimes \\
\hline
\end{tabular}

